\title{
Electrochemical Detection for Sulfite Using Glassy Carbon Electrode Modified by Electrodeposition of Platinum Particles on Nitrogen-Containing Functional Groups
}

\author{
Satrio KUNTOLAKSONO, ${ }^{a}$ Chihiro SHIMAMURA, and Hiroaki MATSUURA ${ }^{\mathrm{a}, \mathrm{b}, *}$ \\ a Department of Life Science \& Green Chemistry, Graduate School of Engineering, Saitama Institute of Technology, \\ 1690 Fusaiji, Fukaya, Saitama 369-0293, Japan \\ ${ }^{\mathrm{b}}$ Department of Life Science \& Green Chemistry, Faculty of Engineering, Saitama Institute of Technology, \\ 1690 Fusaiji, Fukaya, Saitama 369-0293, Japan \\ * Corresponding author: matsuura@sit.ac.jp
}

\section{ABSTRACT}

This study reports a novel electrochemical sensing technique based on electro-deposited Pt particles on glassy carbon electrodes modified with nitrogen atoms containing functional groups (PtNF-GC) electrode for detecting sulfite in aqueous solution. PtNF-GC electrodes have a favorable electrocatalytic activity of sulfite oxidation, which moves the oxidation peak potential to the negative direction of potential unlike Pt disk, a bare glassy carbon electrode and electro-deposited Pt particles on glassy carbon (Pt-GC) electrode. The linear relationship between the oxidation current peak and sulfite concentration is over the range up to $10 \mathrm{mM}$ with a detection limit of $100 \mu \mathrm{M}$. Our prepared PtNF-GC electrode was applied for the sulfite detection in sample solution with favorite recovery of sulfite. Additionally, a possible reaction mechanism of sulfite was discussed.

\begin{abstract}
(c) The Author(s) 2020. Published by ECSJ. This is an open access article distributed under the terms of the Creative Commons Attribution 4.0 License (CC BY, http://creativecommons.org/licenses/by/4.0/), which permits unrestricted reuse of the work in any medium provided the original work is properly cited. [DOI: 10.5796/electrochemistry.20-64061]. Uploading "PDF file created by publishers" to institutional repositories or public websites is not permitted by the copyright license agreement.
\end{abstract}

Keywords : Electrochemical Modification, Sulfite, Electrodeposition, Carbon Surface

\section{Introduction}

Nowadays, electrodes made of carbon material such as glassy carbon (GC; type of 2 dimensional) and carbon felt (CF; type of 3 dimensional) have been widely used in the field of electroanalysis for various factors such as accessibility, low cost, electrochemical stability in various solutions (from low acid to base), wide potential window ${ }^{1}$ and their large surface area. $^{2}$ Furthermore, chemical modification of carbon surface has attracted great interest in various fields such as electroanalytical chemistry. ${ }^{3}$ In fact, functional groups, usually containing oxygen or nitrogen, and delocalized electrons of graphite structures govern acid/base and hydrophilic/hydrophobic properties of a carbon surface.

Recently, our group has developed various methods for electrochemical modification on a carbon surface such as GC and $\mathrm{CF}$. Nitrogen-containing functional groups are capable of forming chains on the surface of $\mathrm{GC}$ electrodes by electro-oxidation treatment process with ammonium carbamate in aqueous medium solution at a high positive electrode potential, ${ }^{4}$ which we call "aminated glassy carbon (AGC)" electrode. In carbon surface modification by electrochemical process, not only primary amine groups (e.g. aromatic amine groups like aniline) but also other nitrogen-containing functional groups (the secondary amine-like groups containing pyrrole type nitrogen and quaternary amine-like moieties containing graphitic quaternary nitrogen) can be introduced onto a GC electrode surface..$^{5}$ Furthermore, our group has reported that an electrocatalytic redox waves between a hydrogen ion $\left(\mathrm{H}^{+}\right)$and a hydrogen molecule $\left(\mathrm{H}_{2}\right)$ were observed at a highly positive potential range after long-term electrochemical reduction of AGC electrodes in sulfuric acid. On electro-reduction of AGC electrode, platinum ions are dissolved from a platinum wire counter electrode electrodeposited on the nitrogen-containing functional groups. ${ }^{6}$ Additionally, our group has reported that the observed hydrogen redox waves are related to mutual redox reactions between hydrazine, diazene, and also diazo groups affiliated to the carbon electrode surface. ${ }^{7}$

Sulfite $\left(\mathrm{SO}_{3}{ }^{2-}\right)$ is a food additive that is widely used in beverages and food ${ }^{8,9}$ to prevent or reduce spoilage due to oxidative processes, controls bacterial growth during production and storage of food,,${ }^{10,11}$ and also controls enzymatic and non-enzymatic reactions while stabilizing functions and conditions. ${ }^{12}$ Sulfites are also used in manufacture of food packaging materials and as a processing aid to sterilize bottles before packaging food and beverages. ${ }^{13}$ However, sulfites are toxic ${ }^{14}$ and harmful to the human body and need to be used within extremely limited amounts. Exceeding the consumption limit may cause headaches, nausea, diarrhea, asthma attacks, stomach irritation, nettle rash, and swelling. ${ }^{15-17}$

Several methods for detecting sulfite such as iodometric titration, ${ }^{18}$ high-performance liquid chromatography, ${ }^{19}$ spectrophotometry, ${ }^{20,21}$ chemiluminescence, ${ }^{22}$ and capillary electrophoresis ${ }^{23}$ have been developed. In contrast, these methods have various disadvantages such as time-consuming process, its high cost, and requirement for pretreatment of a sample. For several years, the researcher has been paid attention on the electrochemical methods focusing on their simplicity, easy operation, rapid detection, and also low cost. The electrochemical methods have been widely used in practical fields for the above reasons.

In this paper, we report a novel electrochemical sensing technique by based on electro-deposited platinum particles on glassy carbon electrodes modified with nitrogen atoms containing functional groups (PtNF-GC) electrode for detecting sulfite. In particular, we described electrocatalytic oxidation of sulfite and also the possibility for utilizing PtNF-GC electrode for detection of sulfite in the voltammetric technique. 


\section{Experimental}

All chemicals used were of analytical reagent grade. Deionized water (Millipore Milli-Q System, Japan) was used to prepare solutions used in this investigation. Sodium sulfite $\left(\mathrm{Na}_{2} \mathrm{SO}_{3}\right)$, sulfuric acid $\left(\mathrm{H}_{2} \mathrm{SO}_{4}\right)$, dipotassium hydrogenphosphate $\left(\mathrm{K}_{2} \mathrm{HPO}_{4}\right)$ and potassium dihydrogenphosphate $\left(\mathrm{KH}_{2} \mathrm{PO}_{4}\right)$ were purchased from Fujifilm Wako Pure Chemical Industries, Ltd. (Osaka, Japan). Ammonium carbamate was purchased from Merck KGaA (Darmstadt, Germany). The glassy carbon (GC) electrode (diameter of $3 \mathrm{~mm}$ ) was obtained from BAS Co., Ltd. (Tokyo, Japan). The electrolyte solution was a $0.1 \mathrm{M}$ phosphate buffer solution (PBS; $\mathrm{pH} 7.0)$.

A potential controlled electrolysis process was performed with a potentiostat/galvanostat (HA-151B, Hokuto Denko Co., Ltd., Japan). A platinum wire and an $\mathrm{Ag} / \mathrm{AgCl}$ ( $3 \mathrm{~mol} / \mathrm{L}$ electrolyte) were used as a counter electrode and a reference electrode, respectively.

The GC electrode was polished with $1.0 \mu \mathrm{m}$ polishing diamond and $0.05 \mu \mathrm{m}$ polishing alumina on the polishing pad, processed by ultrasonic bath treatment (one minute), and rinsed with deionized water. The PtNF-GC electrode was prepared by stepwise electrolysis as follows. First, the GC electrode thus cleaned was processed by electrode oxidation in $0.1 \mathrm{~mol} / \mathrm{L}$ ammonium carbamate aqueous solution at an applied potential of $+1.1 \mathrm{~V}$ for 60 minutes. Next, the electro-oxidized GC electrode was electro-reduced in $1.0 \mathrm{~mol} / \mathrm{L}$ sulfuric acid at $-1.1 \mathrm{~V}$ (vs. $\mathrm{Ag} / \mathrm{AgCl}$ ) for $20 \mathrm{~h}$. During the electrode reduction process of the electro-oxidized GC electrode in sulfuric acid electrolyte, platinum ion dissolved from platinum counter electrode is electrodeposited on the surface of nitrogen atoms containing functional groups introduced GC electrode. All experiments were performed at room temperature.

Electrochemical measurements of sulfite were performed by using an automatic polarization system (HZ-3000, Hokuto Denko., Ltd., Japan) with a three-electrode cell system. An $\mathrm{Ag} / \mathrm{AgCl}(3$ $\mathrm{mol} / \mathrm{L} \mathrm{NaCl}$ electrolyte) and $\mathrm{Pt}$ wire are reference and counter electrodes, respectively.

\section{Results and Discussion}

Electrochemical behaviors of sulfite with the PtNF-GC electrode were investigated by cyclic voltammetry. Figure 1 shows cyclic voltammograms with the different electrode materials: PtNF-GC electrode (a), Pt disk electrode (b), and a bare GC electrode (c) containing $5 \mathrm{mM}$ sulfite in $0.1 \mathrm{M}$ PBS (pH 7.0). Peak potential of sulfite oxidation for each electrode material is explained as follows: (a) PtNF-GC electrode was $+0.56 \mathrm{~V}$, (b) Pt disk electrode was $+0.62 \mathrm{~V}$, and (c) a bare GC electrode was higher than $+1.0 \mathrm{~V}$. These results indicate that the PtNF-GC electrode has favorable electrocatalytic activity and the oxidation peak potential moved to the negative direction of potential, unlike other two electrode materials. This probably indicates that the electrodeposited Pt in collaboration with the nitrogen atoms containing functional groups (such as the primary amine group and other N-containing functional groups) introduced by stepwise electrolysis in ammonium carbamate solution and sulfuric acid function as active sites of the specific electrocatalytic current for sulfite. To achieve this, we investigated the voltammetric properties for sulfite using electro-deposited platinum particles on glassy carbon (Pt-GC) electrode as described in Fig. S1 of the Supporting Information. The peak potential of sulfite oxidation at the PtNF-GC electrode is at $+0.56 \mathrm{~V}$, which is lower than that at the Pt-GC electrode $(+0.70 \mathrm{~V})$ under the same experimental conditions. This fact indicates that the PtNF-GC electrode is superior to conventional electrodes for the electrochemical oxidation of sulfite. In addition, we previously reported that the electrocatalytic activity of the PtNF-GC electrode for hydrogen oxidation did not decrease after ultrasonication performed for $5 \mathrm{~min},{ }^{6}$

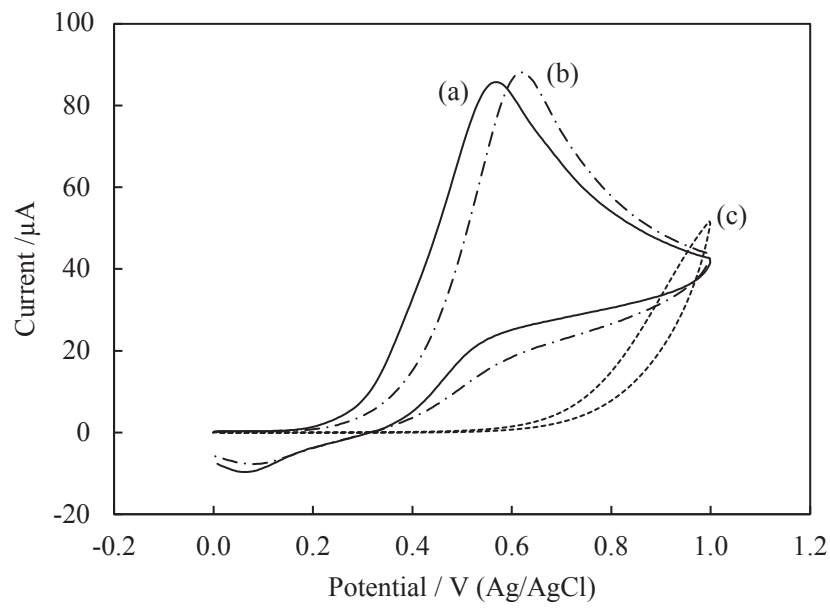

Figure 1. Cyclic voltammograms containing $5 \mathrm{mM}$ of sulfite using the different electrode material (a) PtNF-GC electrode, (b) Pt disk electrode, and (c) bare GC electrode. Supporting electrolyte: $0.1 \mathrm{M}$ phosphate buffer solution ( $\mathrm{pH} 7.0$ ); scan rate $50 \mathrm{mV} / \mathrm{s}$.

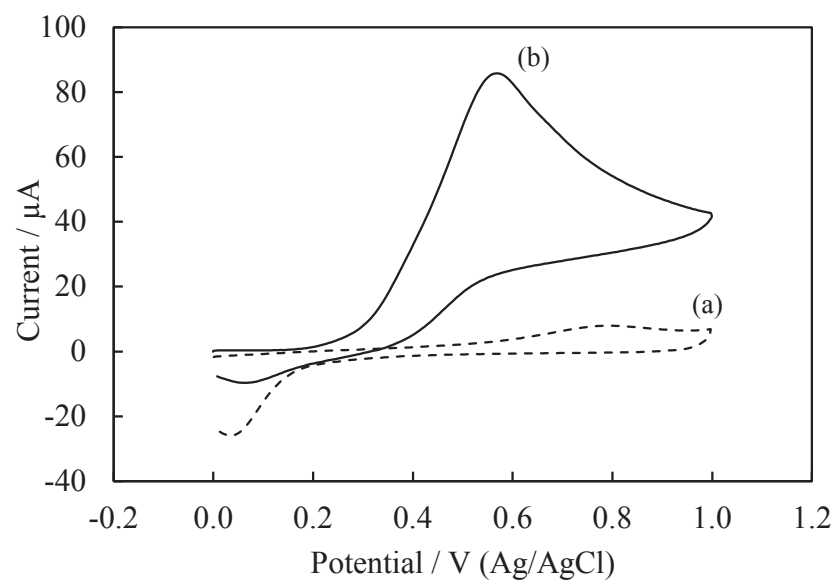

Figure 2. Cyclic voltammograms of PtNF-GC electrode (a) without and (b) with $5 \mathrm{mM}$ of sulfite. Supporting electrolyte: $0.1 \mathrm{M}$ phosphate buffer solution $(\mathrm{pH} 7.0$ ); scan rate $50 \mathrm{mV} / \mathrm{s}$.

which indicates that $\mathrm{Pt}$ particles on nitrogen atoms containing functional groups are tightly immobilized onto the GC surface.

Figure 2 shows cyclic voltammograms of the PtNF-GC electrode without sulfite (a) and with $5 \mathrm{mM}$ sulfite (b). As shown in Fig. 2(a), small and broad oxidation waves with a dominant peak at approximately $+0.80 \mathrm{~V}$ (vs. $\mathrm{Ag} / \mathrm{AgCl}$ ) were observed. These small oxidation waves were expected to correspond to oxide formation at Pt particles in the PtNF-GC electrode. On the other hand, significant oxidation waves were observed in $0.1 \mathrm{M}$ PBS containing $5 \mathrm{mM}$ sulfite (Fig. 2(b)). This electrochemical performance was achieved by the PtNF-GC electrode and considered as an electrochemical oxidation of the sulfite in a test solution. Furthermore, it is assumed that the active sites introduced onto the surface of the GC electrode by two stepwise electrolysis processes (The steps of PtNF-GC electrode preparation such as electro-oxidation and electro-reduction processes) function as an active sites of the electron transfer for the electrocatalytic oxidation for sulfite.

Figure 3(A) shows cyclic voltammograms obtained for various concentration of sulfite by using PtNF-GC electrode. The oxidation peak current was increased with an increase in sulfite concentration up to $10 \mathrm{mM}$. The lower detection limit was evaluated to be $100 \mu \mathrm{M}$. Relationship between the sulfite concentration and the oxidation peak current is shown in Fig. 3(B). The oxidation peak current increased linearly with the linear regression coefficient of 0.9976 . 

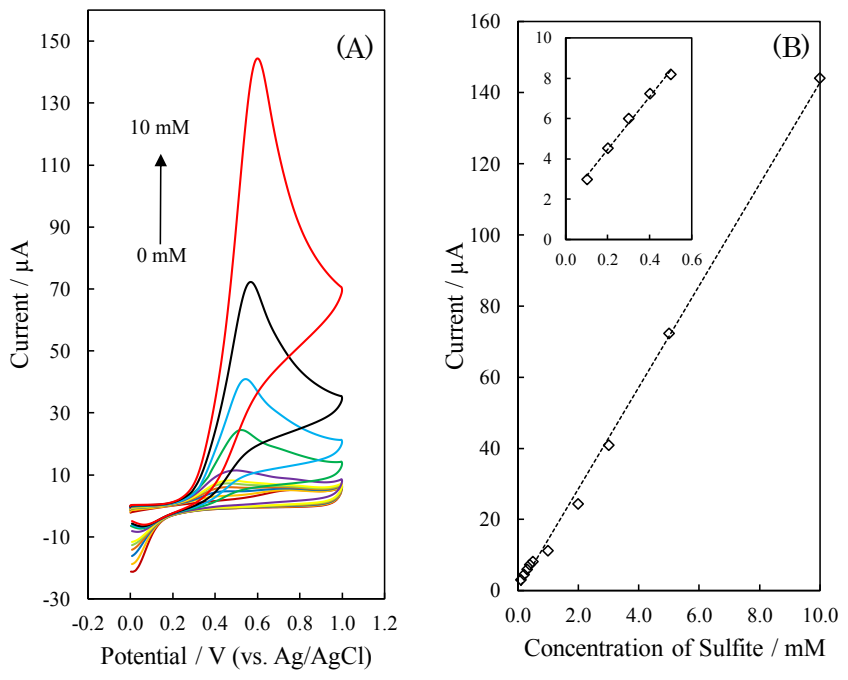

Figure 3. Cyclic voltammograms of PtNF-GC electrode (A) Variation concentration of sulfite from $0 \mathrm{mM}$ to $10 \mathrm{mM}$, (B) The relationship between the concentration of sulfite and the oxidation peak current. Supporting electrolyte: $0.1 \mathrm{M}$ phosphate buffer solution $(\mathrm{pH} 7.0)$; scan rate $50 \mathrm{mV} / \mathrm{s}$.

These results demonstrate stability of a PtNF-GC electrode for electrocatalytic applications where a continuous detection of analytes is performed.

Figure 4 describes electrochemical behaviors of the PtNF-GC electrode at different scan rates $(v)$ from 10 to $500 \mathrm{mV} / \mathrm{s}$ of sulfite in $0.1 \mathrm{M}$ PBS ( $\mathrm{pH}$ 7.0). The oxidation peak current $\left(I_{\mathrm{p}}\right)$ increased linearly with an increase in the scan rate. The oxidation peak current $\left(I_{\mathrm{p}}\right)$ was proportional to the square root of the scan rate (Fig. 4(A)). These results indicate that the reaction system was controlled by sulfite diffusion. Figure 4(B) shows that the calibration curve between peak potential $\left(E_{\mathrm{p}}\right)$ versus $\log (v)$ had a favorable linearity. Thus, it can be concluded that the oxidation peak potential was proportional to the $\log (v)$. As shown in the result, the peak potential is shifted to a more positive potential direction by increasing the scan rate. Since electrode reaction process of the sulfite oxidation is irreversible, the Laviron's equation ${ }^{24}$ was used to estimate the electron transfer numbers $(n)$. Since a totally irreversible electron transfer was assumed, the $n$ was calculated as 1.91, indicating that the electrochemical oxidation of sulfite has two electron path processes. These results make us infer that the electrochemical oxidation reaction of sulfite ${ }^{25}$ on PtNF-GC electrode is expressed as Eq. (1):

$$
\mathrm{SO}_{3}{ }^{2-}+2 \mathrm{H}_{2} \mathrm{O} \rightarrow \mathrm{SO}_{4}{ }^{2-}+2 \mathrm{H}^{+}+2 \mathrm{e}^{-}
$$

In order to evaluate the reaction selectivity in terms of the use of PtNF-GC electrode, we tried to the spike recovery of $5 \mathrm{mM}$ sulfite as shown in Table $\mathrm{S} 1$ of the Supporting Information. The good recovery of sulfite using the possible each interfering substance was obtained. These results reveal that the PtNF-GC electrode is promising candidate for the sulfite detection with good reproducibility, favorable selectivity and acceptable stability.

\section{Conclusion}

A new type of modified electrode, such as the PtNF-GC electrode, has been prepared by stepwise electrolysis for detecting sulfite in an aqueous solution. The PtNF-GC electrode showed a favorable electrocatalytic activity and also lowest peak potential compared with other two electrodes such as the Pt disk electrode and bare GC electrode. The sulfite oxidation peak current $\left(I_{\mathrm{p}}\right)$ was proportional to the square root of the scan rate. Additionally, the relationship between the oxidation peak potential and the $\log (v)$ showed a favorable linearity. The oxidation peak current $\left(I_{\mathrm{p}}\right)$ of

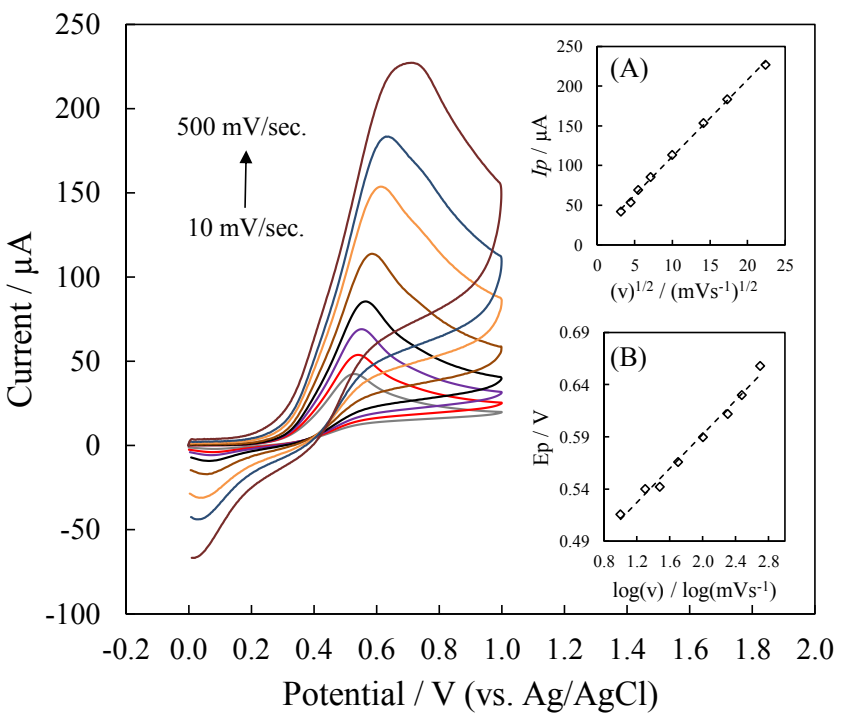

Figure 4. Cyclic voltammograms of PtNF-GC with $5 \mathrm{mM}$ of sulfite at different scan rates $(10$ to $500 \mathrm{mV} / \mathrm{s})$. (A) The linear regression curve of $I_{\mathrm{p}}$ and $(v)^{1 / 2}$. (B) The linear regression curve of $E_{\mathrm{p}}$ and $\log (\mathrm{v})$. Supporting electrolyte: $0.1 \mathrm{M}$ phosphate buffer solution ( $\mathrm{pH} 7.0)$; scan rate $50 \mathrm{mV} / \mathrm{s}$.

sulfite showed a favorable linearity with the concentration of sulfite. These results show that the PtNF-GC electrode has been proved to be highly suitable for detecting sulfite.

\section{Supporting Information}

The Supporting Information is available on the website at DOI: https://doi.org/10.5796/electrochemistry.20-64061.

\section{References}

1. E. Frackowiak and F. Beguin, Carbon, 39, 937 (2001).

2. N. Kishimoto and N. Matsuda, Environ. Sci. Technol., 43, 2054 (2009).

3. R. W. Murray, Electroanalytical Chemistry and Interfacial Electrochemistry (Ed. A. J. Bard), Vol. 13, Marcel Dekker, New York, p. 191 (1984).

4. S. Uchiyama, H. Watanabe, H. Yamazaki, A. Kanazawa, H. Hamana, and Y. Okabe, J. Electrochem. Soc., 154, F31 (2007).

5. A. Kanazawa, T. Daisaku, T. Okajima, S. Uchiyama, A. Kawauchi, and T. Osaka, Langmuir, 30, 5297 (2014).

6. H. Matsuura, T. Takahashi, S. Sakamoto, and S. Uchiyama, Anal. Sci., 33, 703 (2017).

7. S. Uchiyama, H. Matsuura, and Y. Yamawaki, Electrochim. Acta, 88, 251 (2013).

8. A. F. Gunnison, Food Cosmet. Toxicol., 19, 667 (1981).

9. S. Satienperakul, P. Phongdong, and S. Liawruangrarth, Food Chem., 121, 893 (2010).

10. L. Pizzoferrato, G. Di Lullo, and E. Quattrucci, Food Chem., 63, 275 (1998).

11. T. Fazio and C. R. Warner, Food Addit. Contam., 7, 433 (1990).

12. R. Walker, Food Addit. Contam., 2, 5 (1985).

13. K. W. Lien, D. P. H. Hsieh, H. Y. Huang, C. H. Wu, S. P. Ni, and M. P. Ling, Toxicol. Rep., 3, 544 (2016).

14. L. S. T. Alamo, T. Tangkuaram, and S. Satienperakul, Talanta, 81, 1793 (2010).

15. H. J. Suh, Y. H. Cho, M. S. Chung, and B. H. Kim, J. Food Compos. Anal., 20, 212 (2007).

16. S. S. M. Hassan, M. S. A. Hamza, and A. H. K. Mohamed, Anal. Chim. Acta, 570, 232 (2006).

17. D. H. Allen, Food Technol., 73, 506 (1985).

18. G. Monnier and S. Williams, Analyst, 95, 119 (1972).

19. S. Theisen, R. Hansch, L. Kothe, U. Leist, and R. Galensa, Biosens. Bioelectron., 26, 175 (2010).

20. L. J. Wang, Y. H. Tang, and Y. H. Liu, J. Pharm. Anal., 1, 51 (2011).

21. P. D. Tzanavaras, E. Thiakouli, and D. G. Themelis, Talanta, 77, 1614 (2009).

22. R. Rawal and C. S. Pundir, Int. J. Biol. Macromol., 51, 449 (2012).

23. G. Jankovskiene, Z. Daunoravicius, and A. Padaraukas, J. Chromatogr., A, 934, 67 (2001).

24. E. Laviron, J. Electroanal. Chem., 101, 19 (1979).

25. J. A. O'Brien, J. T. Hinkley, S. W. Donne, and S. E. Lindquist, Electrochim. Acta, 55, 573 (2010). 